\title{
Higher Education Challenges: Developing Skills to Address Contemporary Economic and Sustainability Issues
}

\author{
Boštjan Aver ${ }^{1}$, Ajda Fošner ${ }^{1, *}$ and Nikša Alfirević ${ }^{2}$ \\ 1 Faculty of Entrepreneurship, GEA College, 1000 Ljubljana, Slovenia; bostjan.aver@gea-college.si \\ 2 Faculty of Economics, Business and Tourism, University of Split, 21000 Split, Croatia; nalf@efst.hr \\ * Correspondence: ajda.fosner@gea-college.si
}

Citation: Aver, B.; Fošner, A.;

Alfirević, N. Higher Education

Challenges: Developing Skills to

Address Contemporary Economic

and Sustainability Issues.

Sustainability 2021, 13, 12567.

https://doi.org/10.3390/su132212567

Academic Editor: Grigorios L.

Kyriakopoulos

Received: 17 September 2021

Accepted: 12 November 2021

Published: 14 November 2021

Publisher's Note: MDPI stays neutral with regard to jurisdictional claims in published maps and institutional affiliations.

Copyright: (c) 2021 by the authors. Licensee MDPI, Basel, Switzerland. This article is an open access article distributed under the terms and conditions of the Creative Commons Attribution (CC BY) license (https:// creativecommons.org/licenses/by/ $4.0 /)$.

\begin{abstract}
This paper aims to provide brief insight into the economic and sustainability challenges that higher education institutions are facing today globally. It provides a theoretical overview of key trends and challenges of higher education, relevant for the development of a sustainable and resilient European economy and society. We support our theoretical proposition by a bibliometric analysis of previous studies dealing with the 21st-century business skills and the sustainability outlook to be produced by the higher education sector. Our main findings are related to a significant rise of researchers' interest in the topic, along with the multi-disciplinary approach being emphasized, as the academic community seeks how to contribute to the pressing issues of ensuring the integration of sustainability with employers' requirements, related to new skill profiles, relevant for the European transformation toward a more resilient, digital, green economy and society. We evaluate the proposed course of research and provide recommendations to researchers and other higher education stakeholders interested in promoting this educational sector's sustainability and relevance in the 21st century.
\end{abstract}

Keywords: higher education; higher educational institutions (HEIs); skills; competences; sustainability

\section{Introduction}

In this paper, we review the most critical challenges to higher education to provide a theoretical framework, which could help European higher educational institutions (HEIs) contribute to environmental sustainability and the creation of relevant 21st-century skills required by today's employers. This proposition was analyzed by using the bibliomet$\mathrm{ric} /$ scientometric approach and discussed from the higher education sector and policy viewpoints.

This study was motivated by the often mentioned need for transformation and digital transformation of HEIs, followed by the severe reduction of university budgets (not only since the 2008-2012 period). Simultaneously, most governments encourage a higher enrolment, targeting at least $40 \%$ of the 29-34-year generation to graduate while providing less money for a growing number of HEIs. Such financial pressure makes it even more difficult for HEIs to introduce the needed changes, e.g., in terms of hiring top professors and researcher experts, acquiring the latest research infrastructure, and maintaining a proper student-teacher numerical relationship.

As a result, some HEIs drastically increased the tuition fees: they tripled in the UK in 2010-making university studies a privilege again. There are many consolidations, mergers, and university clusters: in Norway, already in 1994, 26 HEIs developed from 98 small colleges [1]. In addition, there is more specialization and collaboration among universities. In France, between 2013 and 2018, nineteen university clusters were created. Let us also point out that successful HEIs are contracting more research and consulting services with the private and public sectors than ever. 
Stronger academic-business partnership is undoubtedly helpful for both sides, with the exception of when it consumes the time a professor is supposed to spend mentoring students. In the Nordic countries, universities have "the third task" - collaboration with companies-and even though many of those universities have no tuition fees, the share of government funding is only between $20 \%$ and $35 \%$ [2]. In Japan, HEIs were divided into several categories and instructed by the government to find independent sources of revenue [3]. Since HEIs are not equally successful in these efforts, there is a growing differentiation among them in many countries. Moreover, many well informed observers claim that the quality of teaching is suffering and that even with improved didactics, this cannot be fully compensated.

HEIs face another challenge-how to incorporate global Sustainable Development Goals (SDGs) into their pedagogical, scientific, and institutional processes. Most of the best universities around the globe are competing in the Times Higher Education THE's Impact Ranking (see also [4]), reflecting, thereby, the degree to which they follow the SDGs, adopted in 2015 by all members of the United Nations. In 2019, THE ranking of 767 universities from 86 countries participated-though $82 \%$ of them are from highincome countries.

These developments indicate that academia is now experiencing growing awareness about the implications of modern, post-industrial civilization for higher education. The intensity and complexity of life in the 21st century require a very different knowledge base and set of skills, including socio-psychological features of young people about to enter the job market. It is not sufficient for a university to reach the highest scientific standards. Nowadays, they are also expected to be capable and motivated to provide young people with values of sustainable development and a sense of responsibility towards society-irrespective of the specific roles they will play in society/economy. Unfortunately, very few governments understand that this requires consistent support and adequate funding.

Turning European Agendas (Green Deal, Strategic Foresight-Towards a more Resilient Europe, Industry 5.0) into practice [5-7] requires new skills and competencies of (corporate) sustainability foresight and futures literacy [8] that do not yet exist even in large corporations and are taught only within a handful of specialized study programs.

\section{Literature Review}

\subsection{Higher Education and Sustainability}

Some people with a more traditional mindset would most probably ask: What does sustainability have to do with higher education? The answer is: it does and should, and-fortunately - things are evolving in this direction, though not equally intensive everywhere. In academia, many people are only now starting to understand that the two are more closely connected than expected on the surface [9].

Higher education institutions can significantly build general sustainability awareness, develop practical insights, and motivate young people to behave responsibly. They can achieve this role by respecting sustainability in two senses:

1. Integrating the concept into their curricula and research, preparing students to become responsible in their future professional roles-in line with corporate social responsibility - as well as in their private lives, as members of society and consumers, by treating the environment, resources, and energy responsibly, as well as treating fairly and ethically other members of the community, as well as animals.

2. Integrating the concept into the nature of operation and functioning of the institutions of higher learning to align themselves with the principle of sustainability, which holds a significant social role, as well, since HEIs are often taken as role models.

Therefore, following the global role and contribution of HEIs to the implementation of SDGs [10,11], we propose the following framework for the assistance of the European higher education community in implementing SDGs. Thereby, we will refer to the three 
commonly identified HEI functions, i.e., education, research, and the 'third mission' of co-operating with the stakeholders and ensuring social development (see also $[12,13]$ )

\subsection{Education for Sustainability}

The fourth SDG refers to ensuring inclusive and equitable quality education and promoting lifelong learning opportunities for all. This goal explicitly calls for actions by HEIs, which should support the implementation of all other SDGs, which has not been well recognized by literature until recently [14]. Hence, education represents an essential strategy in successfully meeting the SDGs, e.g., by pursuing the following (as well as similar/related) courses of action, synthesized from the recent literature [15-17]:

- HEIs should organize short courses/training for lecturers about Education for Sustainable Development Goals.

- $\quad$ HEI departments leaders could become responsible for achieving learning objectives and critical competencies (within the study fields of the department) for SDGs.

- There should be an inter-disciplinary integration of SDG learning objectives and critical competencies in all programs, curriculums, textbooks, and policies.

- Students should receive the knowledge, skills, and motivation to understand and address the challenges of the SDGs not just within the study but also in their private life.

- Student clubs and societies might be encouraged and supported to engage with the SDGs and collaborate on SDG-related events and activities

\subsection{Research for Sustainability}

Research is the basis for understanding all challenges European society is facing today. As a research institution, faculty has one of the most critical roles in translating global SDGs (European Green Deal and all other actions) in national and local contexts, identifying gaps, developing solutions, and measuring the progress. Moreover, research and innovation across social sciences are essential for the successful implementation of most of the SDGs, which could be promoted by following actions, as suggested by recent studies [18-20]:

- Encourage and promote the SDGs as a research topic within the university, including interdisciplinary and transdisciplinary research.

- Encourage students to be involved in green challenges (such as 'ideathons', 'hackathons', and similar events) locally, nationally, and internationally.

- Actively support and incubate innovations for local, national, and international sustainable development solutions.

\section{4. 'Third Mission' and Sustainability}

The SDGs can be successfully achieved by engaging all sectors into the cooperation within HEIs, where universities could have a focal position due to their experience in building capacity and supporting the implementation of SDGs. The social role of universities and the academic community, in general, could be supported by the following actions, belonging to the university' third mission' and referred to by the extant literature [21-24]:

- Align university operational policies with the aims of the SDGs, with a particular emphasis on 'campus greening' initiatives.

- Strengthen public engagement and cross-sectoral dialogue in addressing and implementing the SDGs, focusing on cooperation and co-creation processes.

- Inform the broader community about the university's commitment to the SDGs.

\subsection{Higher Education and Twenty-First Century Skills}

Driven by post-COVID and climate-change realities, companies must make fundamental and permanent changes to how they contribute to society. Successfully meeting the need for action on a sustainable, human-centric, and resilient European industry requires leaders equipped with skills to look, understand and act for the long-term good of the company and society, as well as to fit the existing, but also the foreseeable EU policy frameworks [25]. 
Among the topics discussed later in education, the skills and competencies needed by the modern labor market strongly dominate, and the increasing speed and scope of change are the reasons behind. It is generally recognized that Nordic countries have accepted this challenge earlier and more readily than many others.

The fundamental problem characterizing most European countries is that employers pay graduates according to positions, defined primarily by the type of a formal degree, and students are motivated to obtain formal degrees, which does not necessarily imply a set of competencies and skills. This has links to the concept of traditional university-with a very different social function: preparing the future elite in a predominantly illiterate society.

Much higher education staff are still sharing the traditional mentality — understanding their role to be successful when they are passing the best knowledge in their domain onto their students, while paying little attention to the competencies and skills required from the labor market today, let alone tomorrow. These gaps between the labor market requirements and the actual competencies of graduates remain a significant challenge in most European countries (not so much in Scandinavia, in the US, and several Asian countries). Too many university professors are not being offered practical assistance and support in modernizing their teaching. This is considered their responsibility, which coincides with another oldfashioned approach - treating each subject strictly separately, leaving limited space for interdisciplinary and inter-subject perspectives and activities. This is well illustrated by the curricula of most universities and programs on individual issues.

Recognizing both the complexity of skills policies and the potential for peer learning, the OECD [26] has developed a global skills strategy, shifting its focus from traditional higher education tracks to lifelong learning and skills maintained over the lifetime.

Let us point out that this is a problem involving the respective authorities and the leadership of universities and their departments. In the first step, it is necessary to evaluate what should be done by the responsible government institutions and their policies and, of course, what needs to be done by universities and the professors themselves.

The intensified changes in the 21st century-compared to earlier centuries-is the reason why nothing can be found in vast education literature referring to, for example, the «20th-century skills». And which are the 21st-century skills required in the modern social and technological environment, to be developed already through education, including university, but also acquired through Life Long Learning? After reviewing abundant literature on the subject, we could decide to adopt the summary proposed by Stauffer [27], with the following twelve skills and competencies, grouped into three categories:

Learning skills:

1. Critical thinking;

2. Creativity;

3. Collaboration;

4. Communication.

Literacy skills:

1. Information literacy;

2. Media literacy;

3. Technology literacy.

Life skills:

1. Flexibility;

2. Leadership;

3. Initiative;

4. Productivity;

5. Social skills.

Except for technology literacy, none of these skills are entirely new, but they have never been declared essential components of quality education. Now they are recognized in education science as critically important for people entering today's labor market and wanting to be successful. 
The other big question is how the teachers will develop all these skills with their students. One general observation is necessary at the start, namely that the professor/teacher was respected in the past, simply because of their position and academic status/title. This is no more the case- students must feel their professors' caliber and their motive to be accepted on account of their capability to connect with them, not only as a physical person but also as a digital partner.

To be accepted and respected by students, the teacher has to manifest a comparable efficiency level in utilizing digital methods of finding and sharing information online and communicating with students online. Only on this basis can a proper relationship be expected to develop, as the students will treat their professors as senior partners in the new technological era. Without it, professors will be perceived by students as knowledgeable people but belonging to another time. This could create a significant gap, preventing the creation of contemporary educational practice/experience.

Here are some beneficial proposals by a digital native, professor T. Palmer, listing the significant characteristics of a high-quality 21st-century educator [28]:

1. Learner-centered classroom and personalized instruction;

2. Students as producers;

3. Learn new technologies;

4. Go global;

5. Smartly use smartphones;

6. Blog;

7. Go digital;

8. Collaborate;

9. Use Twitter chats;

10. Connect;

11. Project-based learning;

12. Build your positive digital footprint;

13. Code;

14. Innovate;

15. Keep learning.

In general, corporate foresight and creating and managing future scenarios are not yet part of HEIs' curricula or established as standard modules for professional development related to sustainability practices in organizations. At the same time, corporate foresight has in the latest years begun a movement from being a top management tool to becoming a broader stakeholder-driven process. Hybrid methods with a high degree of engagement, interaction, and immersion have shown a high potential in bringing onboard more stakeholders and advance ownership on the deliverables.

\subsection{The Economic and Social Roles of Higher Education}

Skills and competencies are also critical within the ongoing transformation towards a more sustainable economy. Moreover, they are essential to anticipate and deal with unintended consequences of innovation. Sustainability foresight competencies require combining empirical research skills with hermeneutic skills to interpret, contextualize and evaluate individual findings and derive mid-range visions as directives for collaboration. These skills and competencies are rarely taught at European HEIs (with some exceptions in, for example, Finland, Germany, France).

Many industries in Europe face a skills shortage when it comes to strategic foresight for sustainability. Strategic foresight is a precursor for visioning on leadership and product/service level, strategic decision-making in general and organizational integration. Students and industries have difficulties grasping how to work systematically with plausible and preferred green future scenarios. 
Driven by post-COVID and climate-change realities, employers are required to make fundamental and permanent changes. Here, skills and competencies are critical within the ongoing transformation towards a more sustainable, resilient, digital economy. They are also essential to anticipate and deal with unintended consequences of innovation (which is critical for sustainability-oriented innovation).

Current education in most European countries—both management schools and product/service design schools-fails in terms of:

- Step-by-step hybrid learning process and methods to advance foresight for sustainability regardless of the specific area of concern.

- Availability of content/materials for higher education institutions.

- Qualified people to deliver the education.

- Using the latest thinking in hybrid, digital, and human-centered education methods to support student-driven or stakeholder-driven engagement.

Addressing the social challenges, local initiatives, and interventions to reduce environmental harm and social upheaval will not suffice. Creating novel products, services, and business models to create shared value falls short [29] to make the net positive impact that business can contribute. Instead, this requires building an organizational culture based on values and managing innovation with practices and methods that combine a sense of direction with foresight and action. Let us point out that a value-based approach is a key for sustainable development goals—shared values ensure commitment and persistence to achieve desirable outcomes.

In line with the previous arguments, HEIs can contribute to the desirable future by following the suggested steps:

- Building a community of outstanding experts for sustainability foresight and crowdsource insights, for recognizing challenges and good practices.

- Gather and review complementary knowledge, skills, methods and identify critical challenges within local/national industry, innovation, and sustainability.

- Engage practitioners/experts in co-creating tailored solutions to address the abovementioned challenges.

- Develop prototypical solutions, which should be iteratively tested and refined with representatives of the industrial partners who provide feedback and suggestions for improvement. There are ample opportunities to develop innovative industrial solutions within the current EU frameworks, such as Horizon Europe, Inter Reg, and other funding schemes.

These arguments lead toward a proposition that the current economic and social trends require a transformation of higher education toward a multi-disciplinary cooperation with the employers (industry) and policy communities at all levels, directed toward creating innovative skillsets and ensuring sustainable development. If supported by the data on existing research, this proposition could serve as a recommendation for future research in higher education trends and challenges. To support such a proposition, as a recommendation for future empirical research, we performed several bibliometric analyses of the extant body of knowledge to see if the research trends in the last five years support our hypothesized direction of higher education development. The analyses are based on:

- assessment of research trends, provided by Elsevier SciVal, a scientometric tool, enabling the evaluation and benchmarking of research trends and performance, based on Elsevier Scopus data;

- detailed analysis of bibliometric data, related to Clarivate Web of Science (WoS)and Elsevier Scopus-indexed publications, identified based on the proposed terms, describing the research trends in the extant literature related to higher education, sustainability, and 21st-century skills. 


\section{Methodology}

The empirical analysis is performed in two steps: the first step is based on a highlevel analysis of research publications, which could be associated with higher education sustainability and 21st-century skills. In this part of empirical research, we used an entire body of Elsevier Scopus-indexed publications related to the relevant Sustainable Development Goals (SDGs) and analyzed them using the Elsevier SciVal scientometric tool. The analysis is performed for the preceding five-year period (2016-2020).

This analysis relies on mapping relevant SDGs to the extant body of research, which proved to be a proper bibliometric strategy [30]. Elsevier SciVal uses a mapping, developed by the SDG Research Mapping Initiative, as a result of cooperation among Elsevier, Aurora Universities Network, University of Auckland, and University of South Denmark [31]. The relevance of such a mapping is acknowledged by its use as a data source for the Times Higher Education (THE) in its Impact Rankings, showcasing the contribution of the world's universities toward the SDGs [32].

In the second step of the empirical analysis, we further analyze the relevant publications and bibliometric trends related to our topics of interest for the same period (2016-2020). In this part of the research, we follow the steps of the generic bibliometric/scientometric research, recommended by Ananiadou, Procter, and Thomas [33], consisting of (a) retrieval, (b) identification, (c) screening and mapping, and (d) synthesis of research results. The obtained empirical results are expected to show both rigorous support to our research proposition and practical guidance for future studies. Namely, Zupic and Cater [34] note that bibliometric analysis proves a valuable tool in mapping the structure of the extant research and the trends in its development and inter-dependency. Visualizations, based on clustering of bibliometric networks, can provide insights, which would be difficult to observe when analyzing a large corpus of literature [35]. For this purpose, we use the bibliometric tools, available online from Clarivate Web of Science and Scopus databases, as well as one of the leading bibliometric visualization tools-VOS Viewer, created by Van Eck and Waltman [36], serving as researchers with the University of Leiden CWTS research center.

We use the body of scientific publications, referred by the two largest citation databases-Clarivate Web of Science (WoS) and Elsevier Scopus. This was done to provide an in-depth coverage of the extant literature relevant to our research proposition on sustainability and 21st-century skills in higher education.

To capture a broad overview of relevant publications, we developed two inclusive search strings for both databases. We tried to include all publications related to the topics of sustainability and developing 21st-century skills by using the following queries:

- WoS advanced search query: (ALL = ("sustainab*" AND “higher educ") OR ALL = ("21 century skill ${ }^{* \prime}$ AND "higher educ*"))

- Scopus advanced search query: TITLE-ABS-KEY ("sustainab" AND "higher educ*") OR ("21st century skill*" AND "higher educ*").

The initial WoS query produced 27,732 results, which were further filtered for the observed five-year period (2016-2020), in which the WoS search engine identified a total of 17,593 relevant publications. Out of those, we selected the original research papers and reviews, appearing in research journals, as the most prominent outlets of scientific publishing. This further reduced our WoS publication corpus to 13,131 documents. The Scopus query produced 7545 results, which were further filtered for the 2016-2020 period, in which 3817 publications were identified as relevant. Out of those, our final corpus of Scopus publications, in analogy to the previously described WoS procedure, consists of 2497 documents published as original studies or reviews, appearing in scientific journals, referred by Scopus. 


\section{Results and Discussion}

The first step of our empirical strategy involves producing a high-level analysis of scholarly publications in five preceding years (i.e., in the 2016-2020 period), which are recognized as relevant for our research proposition and associated with the relevant SDGs. Our mapping to the broad topics of sustainability and relevance of higher education for employers include SDG 4 (Quality Education), SDG 6 (Clean Water and Sanitation), SDG 7 (Affordable and Clean Energy), SDG 11 (Sustainable Cities and Communities), SDG 12 (Responsible Consumption and Production) and SDG 13 (Climate Action). Figure 1a-f show an increased research interest in the selected SDGs throughout the 2016-2020 period, including the total number of published research items referred by Elsevier Scopus. Out of the relevant SDGs, the highest research interest is recorded for the fields of sustainable energy (Figure 1c), followed by sustainable cities and communities (Figure 1d), clean water (Figure 1b), climate change (Figure 1f), quality education (Figure 1a) and sustainable consumption and production (Figure 1e).

Collaboration patterns in the research, related to relevant SDGs, can also be tracked by Elsevier SciVal, with Table 1 reporting the international and academic-corporate collaboration metrics for the 2016-2020 period.

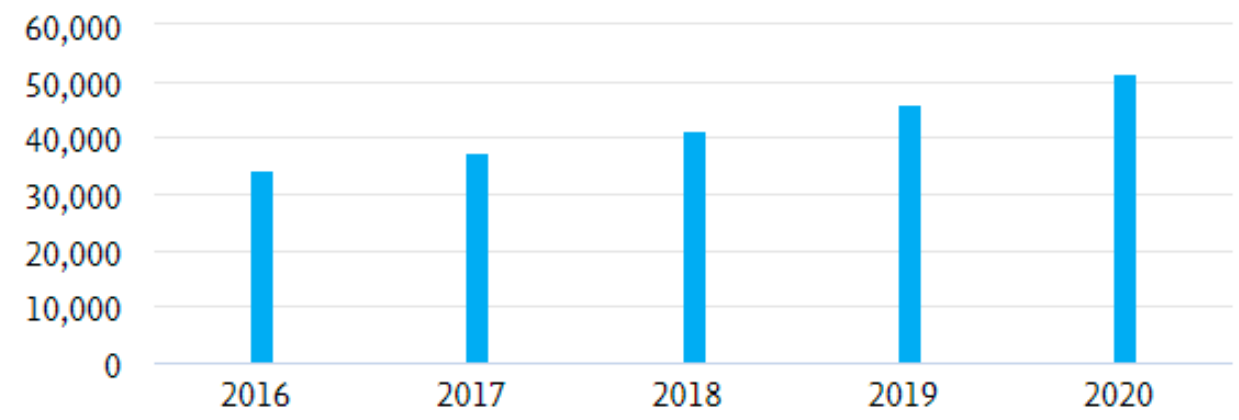

(a)

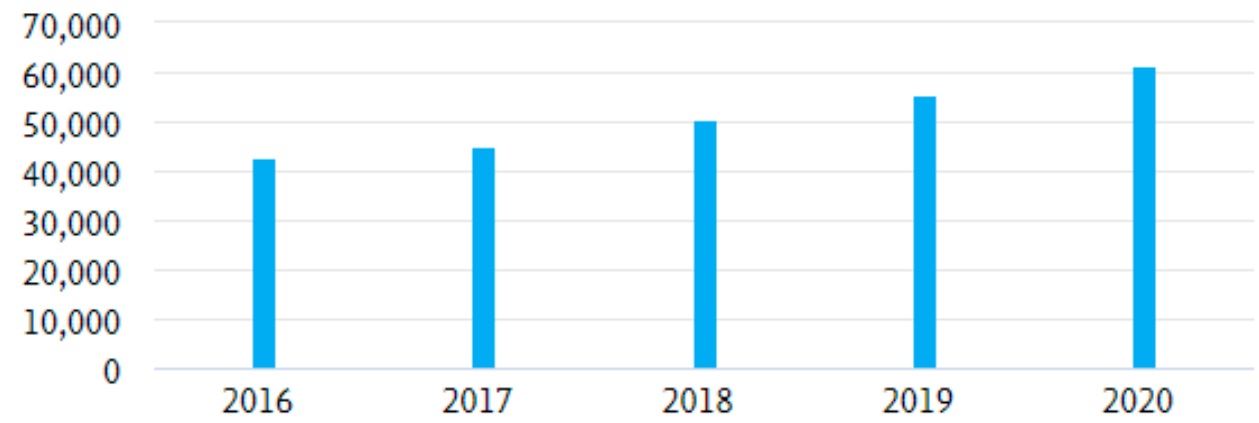

(b)

Figure 1. Cont. 


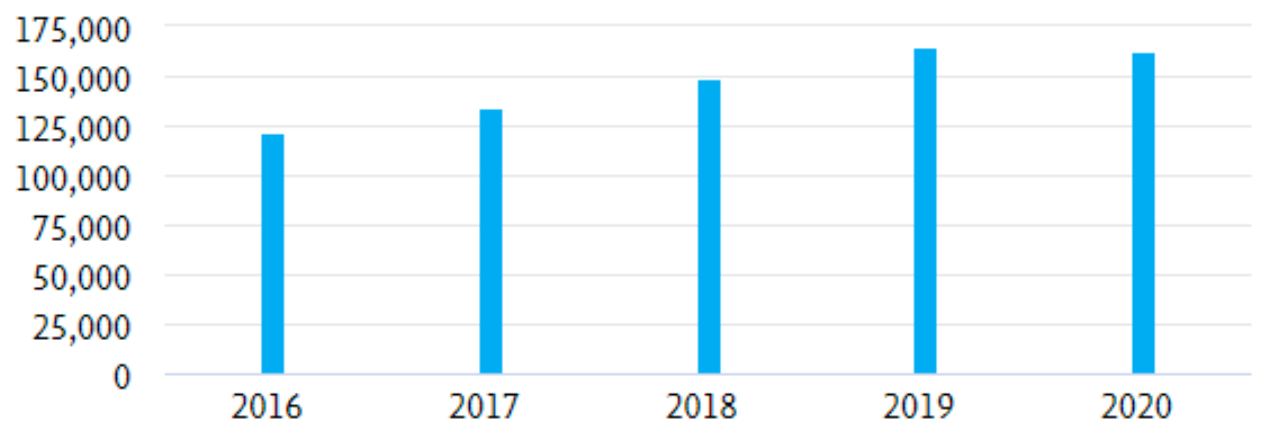

(c)

100,000

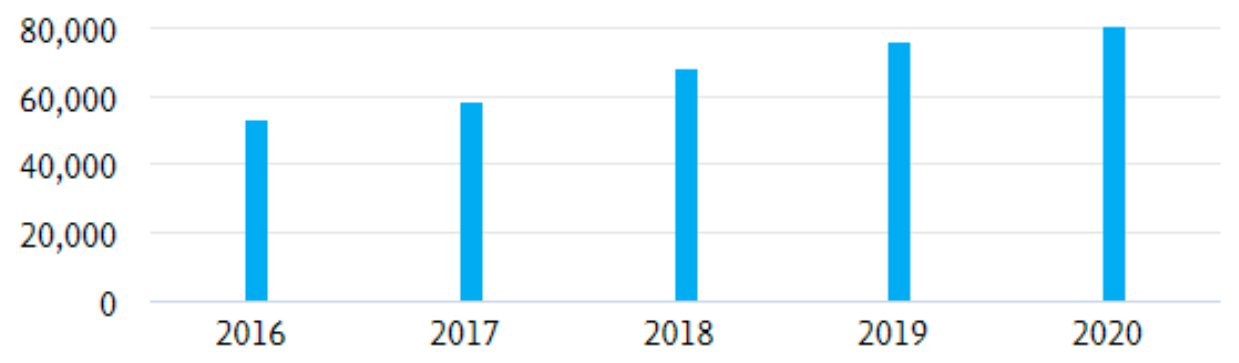

(d)

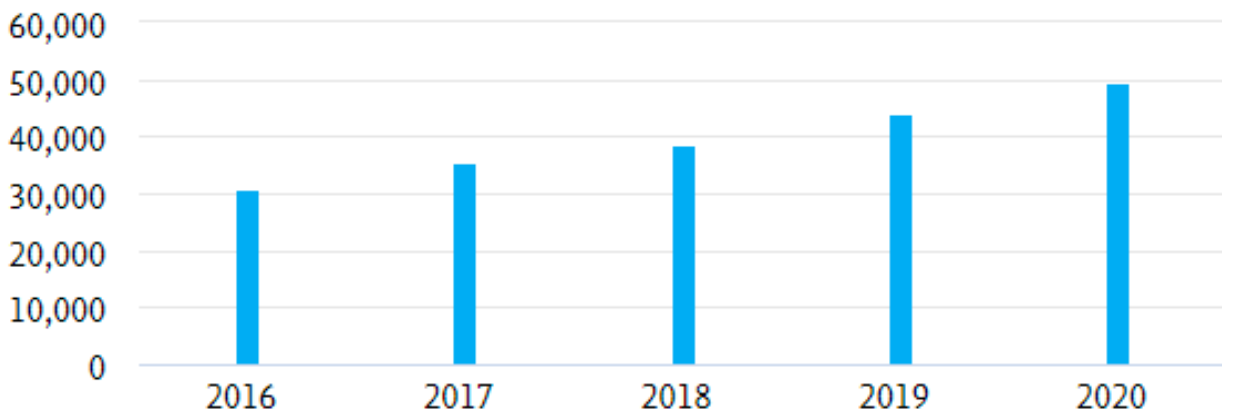

(e)

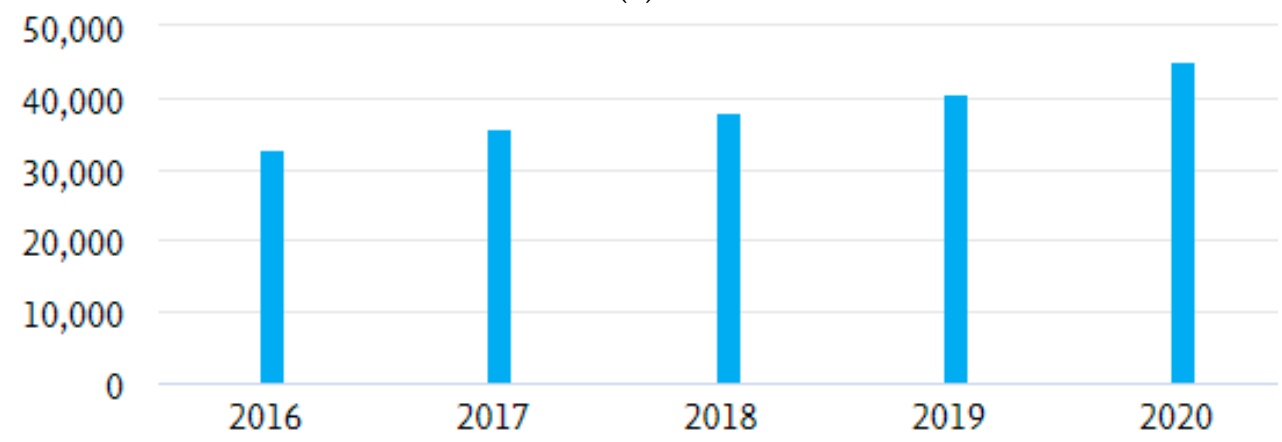

(f)

Figure 1. (a). SDG4-related 2016-2020 research output (210,989 total publications). (b). SDG6related 2016-2020 research output (264,807 total publications). (c). SDG7-related 2016-2020 research output (731,457 total publications). (d). SDG11-related 2016-2020 research output (336,506 total publications). (e). SDG12-related 2016-2020 research output (198,075 total publications). (f). SDG13related 2016-2020 research output (221,759 total publications). Source: Elsevier SciVal. 
Table 1. Collaboration in education- and sustainability-related publications, referred by Scopus, in the 2016-2020 period (as mapped to relevant SDGs).

\begin{tabular}{|c|c|c|c|c|}
\hline SDG & $\begin{array}{c}\text { International } \\
\text { Collaboration } \\
\text { (\% of } \\
\text { Publications) }\end{array}$ & $\begin{array}{c}\text { Field-Weighted } \\
\text { Citation Impact } \\
\text { (Int'l. Collab. vs. } \\
\text { Non-Collab.) }\end{array}$ & $\begin{array}{l}\text { Academic- } \\
\text { Corporate } \\
\text { Collaboration (\% } \\
\text { of Publications) }\end{array}$ & $\begin{array}{c}\text { Field-Weighted } \\
\text { Citation Impact } \\
\text { (Corpor. Collab. vs. } \\
\text { Non-Collab.) }\end{array}$ \\
\hline $\begin{array}{l}\text { SDG } 4 \\
\text { (Quality Education) }\end{array}$ & 15.1 & $1.49 / 0.75$ & 0.7 & $1.82 / 1.01$ \\
\hline $\begin{array}{l}\text { SDG } 6 \\
\text { (Clean Water and Sanitation) }\end{array}$ & 24.5 & $1.59 / 0.68$ & 1.8 & $1.28 / 1.14$ \\
\hline $\begin{array}{l}\text { SDG } 7 \\
\text { (Affordable and Clean Energy) }\end{array}$ & 23.2 & $1.97 / 0.84$ & 4.3 & $1.52 / 1.39$ \\
\hline $\begin{array}{l}\text { SDG } 11 \\
\text { (Sustainable Cities and Communities) }\end{array}$ & 22.2 & $1.67 / 0.78$ & 2.2 & $1.60 / 1.13$ \\
\hline $\begin{array}{l}\text { SDG } 12 \\
\text { (Responsible Consumption and Production) }\end{array}$ & 24.5 & $1.78 / 0.9$ & 1.9 & $1.51 / 1.26$ \\
\hline $\begin{array}{l}\text { SDG } 13 \\
\text { (Climate Action) }\end{array}$ & 31.1 & $1.91 / 1.01$ & 2.9 & $1.58 / 1.42$ \\
\hline
\end{tabular}

Source: Elsevier SciVal.

Although the number of research collaborations, especially with the corporate sector, in the relevant SDG research, is still relatively low, its benefits are visible when the impact of such research is assessed. For this purpose, we used the Field-Weighted Citation Impact (FWCI) metric, which can be easily interpreted, as it represents the number of citations received (for any group of research documents) in the 3-year window when compared to the number of citations expected in the given research field. Thus, the metric is accessible to the broader public, as it can be interpreted by comparing the obtained value to 1.0, representing the field average. FWCI is a relative metric, thus enabling the comparison of different scientific fields, having intrinsic differences in the citation patterns. Higher FWCI values, both for the cases of international and corporate collaboration, show the benefits of multi-national and multi-sector research in our analyzed fields. With the increasing research interest in those fields is accounted for, as demonstrated by the growing number of publications related to relevant SDGs, preliminary support for our proposition is obtained.

In the second step of the empirical research, we analyzed the extant body of literature, referred by Clarivate WoS and Elsevier Scopus databases of scholarly literature.

We started the analysis by looking into the publications indexed by the Clarivate Web of Science database. The number of publications with the selected keywords and the number of received citations show a steady increase since 2016 (see Figure 2a,b), confirming the interest of researchers in the analysis of both sustainability and the business relevance of higher education. The readers should note that this analysis has been performed separately for the two successive periods (2016-2018, presented by Figure 2a; 2019-2020, presented by Figure 2b), as Web of Science does not permit the citation analysis for more than 10,000 records.

The most significant feature of the obtained results is multi-disciplinarity, which resonates with the often discussed role of higher education in addressing the wicked problems of the 21st century, including the sustainable development, innovation, and production of human capital for the contemporary economy and society [37-39]. A multidisciplinary approach to research and transboundary education is required to deal with these challenges to the modern society [40], which is especially valuable when dealing with crises, such as those encountered in the last five years in the EU-more specifically, with the massive inflow of migrants [41], COVID-related economic challenges [42], and other relevant issues. The multi-disciplinarity of the analyzed research topics is illustrated by Table 2. Most studies referenced in Web of Science belong to the green science and technology, or the environmental sciences/studies fields, followed by educational research. 


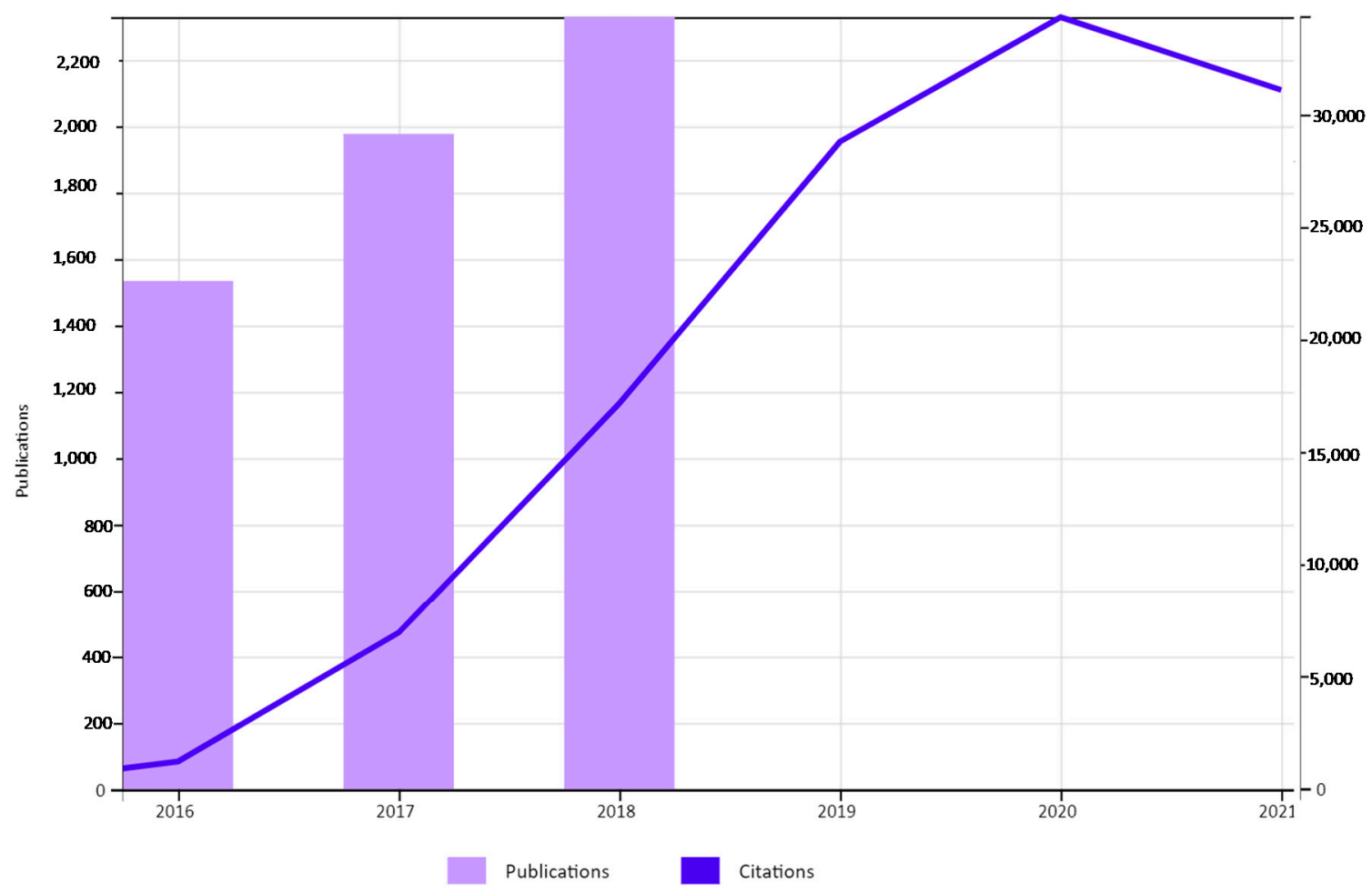

(a)

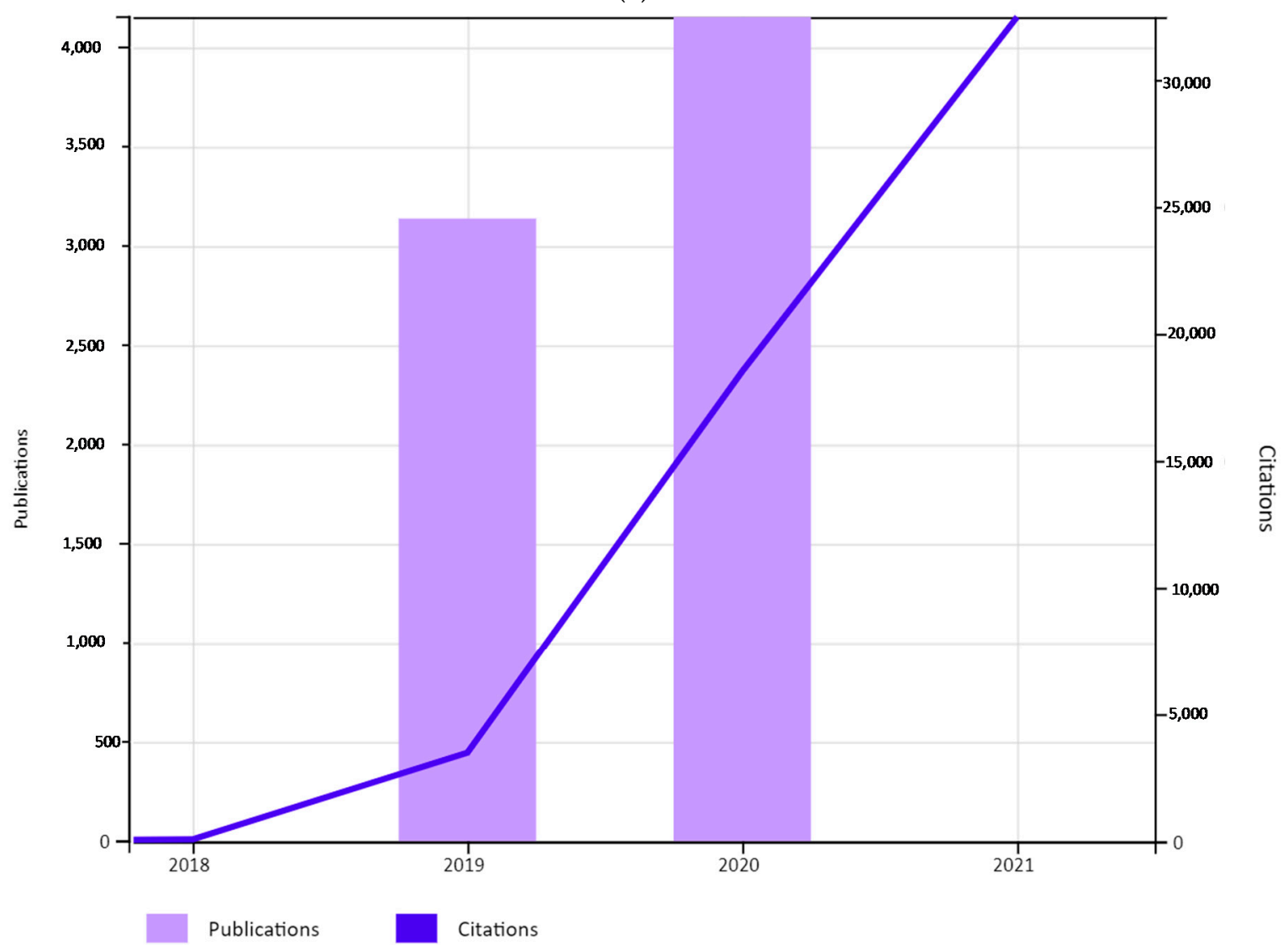

(b)

Figure 2. (a) Number of WoS documents and citations on the research topic (2016-2018). (b) Number of WoS documents and citations on the research topic (2019-2020). Source: Clarivate Web of Science. 
Table 2. Top 25 WoS disciplines/categories involved in the research topic.

\begin{tabular}{|c|c|c|}
\hline WoS Discipline/Category & WoS Record Count & $\%$ of 13.131 Records \\
\hline Environmental Sciences & 3042 & 23.167 \\
\hline Environmental Studies & 1674 & 12.748 \\
\hline Education Educational Research & 1632 & 12.429 \\
\hline Energy Fuels & 996 & 7.585 \\
\hline Chemistry Multidisciplinary & 906 & 6.900 \\
\hline Engineering Chemical & 882 & 6.717 \\
\hline Engineering Environmental & 838 & 6.382 \\
\hline Materials Science Multidisciplinary & 724 & 5.514 \\
\hline Chemistry Physical & 511 & 3.892 \\
\hline Plant Sciences & 388 & 2.955 \\
\hline Multidisciplinary Sciences & 362 & 2.757 \\
\hline Management & 324 & 2.467 \\
\hline Biotechnology Applied Microbiology & 300 & 2.285 \\
\hline Water Resources & 291 & 2.216 \\
\hline Nanoscience Nanotechnology & 251 & 1.912 \\
\hline Ecology & 244 & 1.858 \\
\hline Agronomy & 234 & 1.782 \\
\hline Forestry & 234 & 1.782 \\
\hline Engineering Civil & 233 & 1.774 \\
\hline Business & 231 & 1.759 \\
\hline Physics Applied & 231 & 1.759 \\
\hline Engineering Multidisciplinary & 227 & 1.729 \\
\hline Construction Building Technology & 212 & 1.615 \\
\hline Economics & 201 & 1.531 \\
\hline
\end{tabular}
Source: Clarivate Web of Science.

Publications indexed by the Elsevier Scopus database also show a steadily increasing trend in the research output (see Figure 3), comparable to the WoS-based analysis.

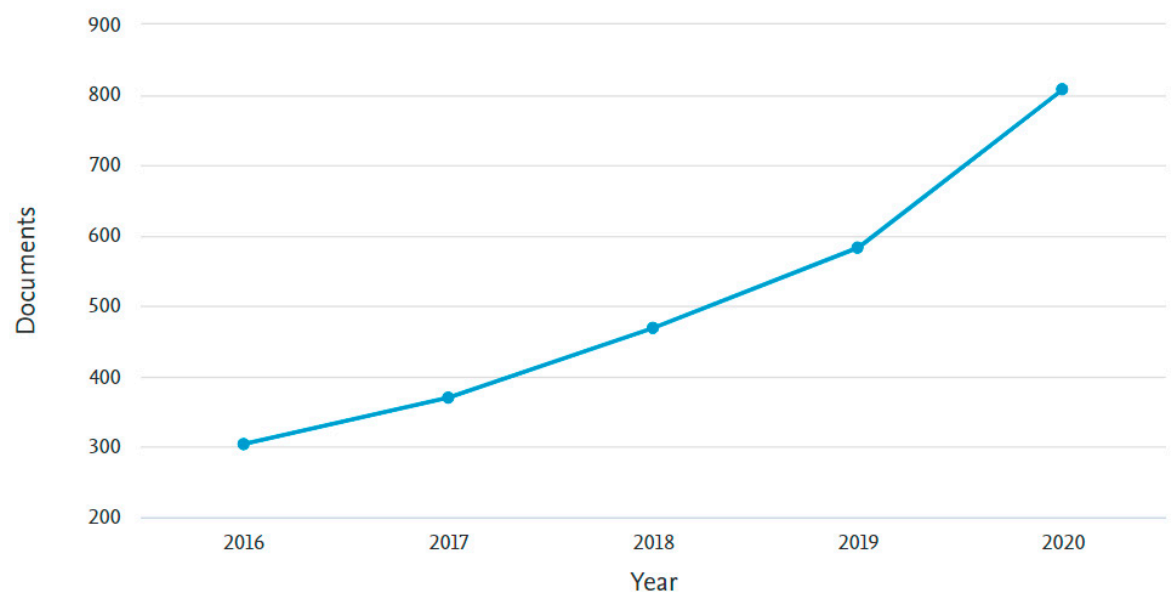

Figure 3. Number of Scopus documents on the research topic. Source: Elsevier Scopus. 
The number of Scopus citations on the research topic also confirms the increasing researchers' interest in the proposed topic (see Figure 4). The rising citation pattern is comparable to the WoS analysis. Once again, the analysis was performed for the two subsequent periods (2016-2018 and 2019-2020) due to the Scopus reporting limitations, which are similar to those of Web of Science.

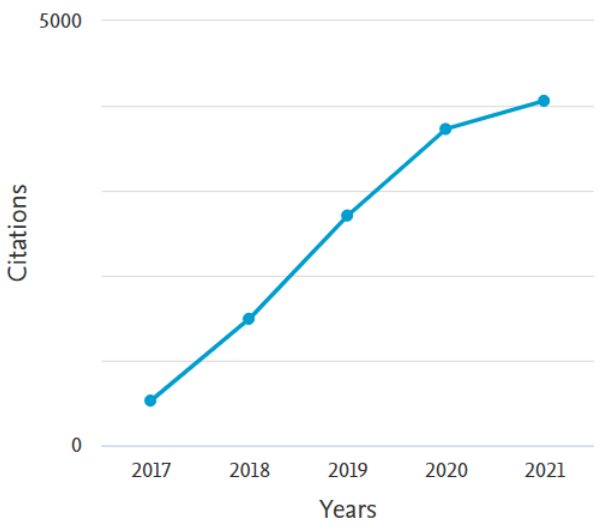

Scopus Citations received for the $2016-2018$ corpus

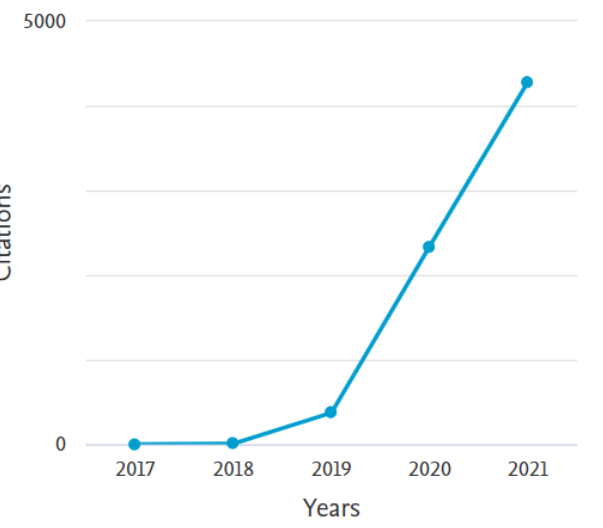

Scopus Citations received for the $2019-2020$ corpus

Figure 4. Number of Scopus citations on the research topic corpus (2016-2018 and 2019-2020). Source: Elsevier Scopus.

The multi-disciplinarity of this research corpus, as seen by Scopus (see Figure 5), is, once again, comparable to the results of the WoS analysis, confirming our proposition of the value of collaboration and multi-disciplinarity in the research of sustainability and business relevance of higher education.

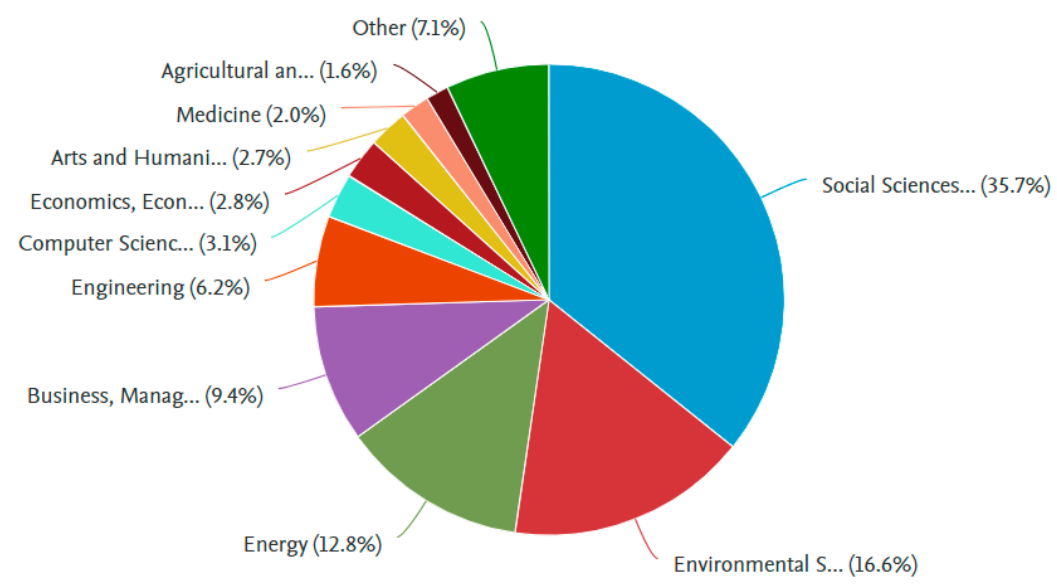

Figure 5. Disciplines involved in the research topic (Scopus documents). Source: Elsevier Scopus.

To analyze the structure of extant research, we downloaded the WoS corpus and performed the co-occurrence analysis of author-supplied keywords, which were processed and visualized using the VOS Viewer bibliometric software and the methodological approach, suggested by van Eck and Waltman [43]. This is a popular and frequently used bibliometric procedure that uncovers the patterns of research items grouped from the researchers' perspective (see Figure 6). The obtained research map represents the major science fields (with the education research, represented by red color, energy and climate studies by yellow, agricultural production and biodiversity studies by blue, waste management studies by purple, and environmental science by green), previously identified by the WoS and Scopus tools. However, it shows a high level of inter-connectedness, which supports our proposition on the need for an inter-disciplinary approach and stakeholder cooperation. 


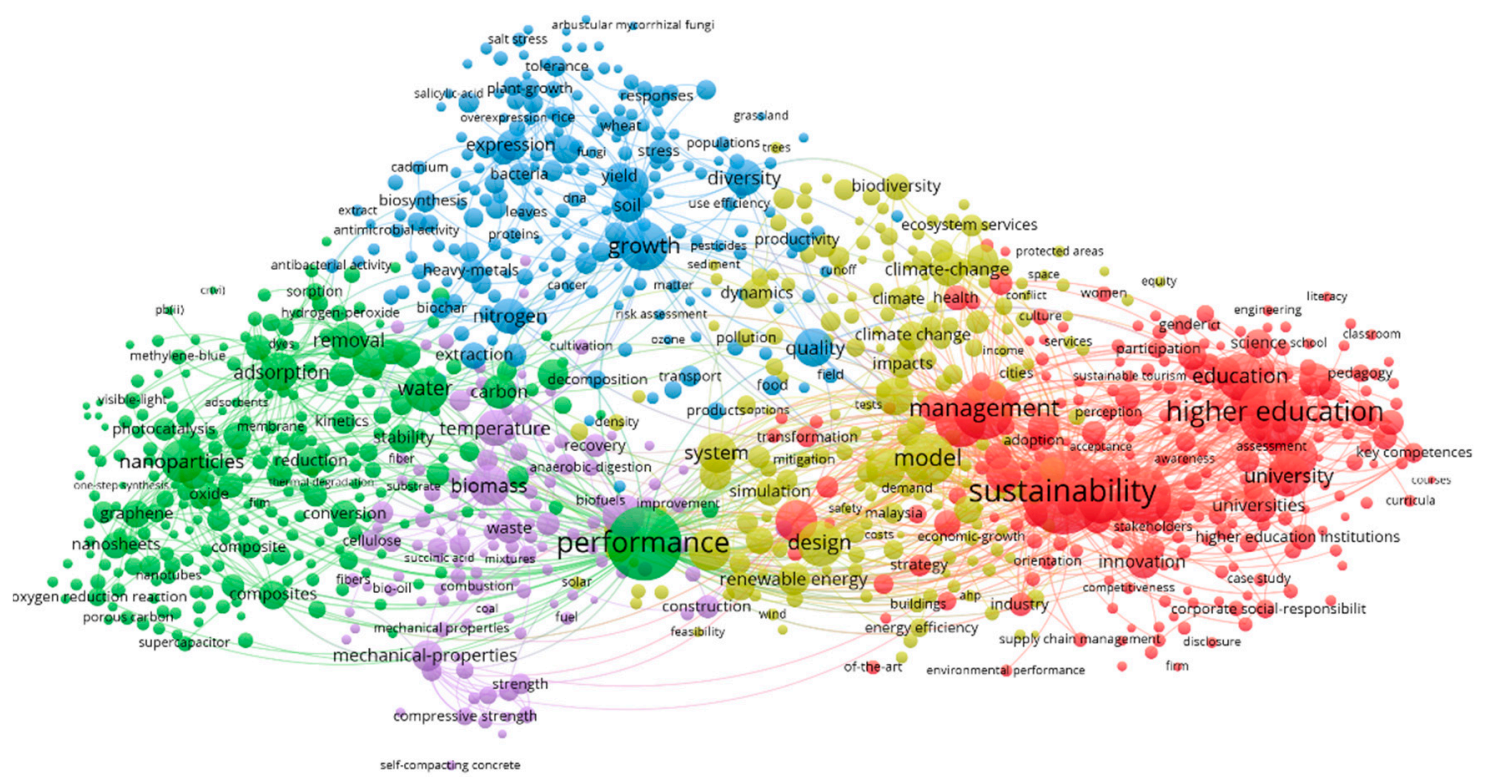

Figure 6. Web of Science publications clustered according to author-supplied key term co-occurrences. Source: Authors (visualization performed in VOS Viewer).

In addition, text mining of the analyzed publications' titles in the WoS corpus was performed to create a 'realistic' map of key term co-occurrences. This approach facilitates knowledge discovery and uncovers the details, which could be overlooked otherwise [44], especially when coupled with bibliometric visualization tools, such as the previously described VOS Viewer. The text mining uncovers much more beneficial results, as there seem to be only four clusters of research items: one focused on teaching and learning about sustainability, as well as other aspects of achieving sustainability in higher education (green); one focused on eco-friendly production methods and processes (red); one analyzing the agricultural production and bio-diversity (blue), as well as a small cluster of studies from physics (yellow).

Text mining results show that the inter-disciplinary collaboration is much lower than specified by authors' keywords. There is a high level of collaboration within the technical and natural sciences. In contrast, the (higher) education studies seem to be somewhat focused on their topics, with only a few links to the other fields of sustainability research (see Figure 7). Text mining, based on both titles and abstracts, could have provided even more informative results. However, the authors were unable to perform it due to many records and a high level of technical capabilities, which were not available at the time of conducting the study.

Unfortunately, since VOS Viewer is a scientometric tool, specialized in visualization, its limitations restrict us in a more detailed reporting, related to the cluser composition and the empirically obtained keywords. Therefore, in the supporting materials, we provide both high-resolution images of the obtained visualizations, as well as the VOS Viewer map and network files, which can be used by readers to re-create the visualizations, by using the this free tool (available from: https://www.vosviewer.com/download; accessed on 10 November 2021).

According to the year of publication, the obtained results were re-analyzed by a science mapping algorithm, clustering the analyzed documents (see Figure 8). This analysis shows that within the education research cluster (see the red cluster in Figure 6), the emphasis moves toward innovation and the analysis of sustainability as a component of the sector's Corporate Social Responsibility (CSR).

The analysis of crucial term co-occurrence dynamics, performed using the text mining of publications' titles, uncovers additional research trends. It seems that within the education research cluster, researchers move their focus from the sector-wide and institu- 
tional studies of education sustainability, success criteria, and examples of good practices, including the curriculum and stakeholder engagement, toward the discussion(s) of student perceptions and SDGs, with systematic theory reviews occupying a significant position among the methodological approaches (see Figure 9).

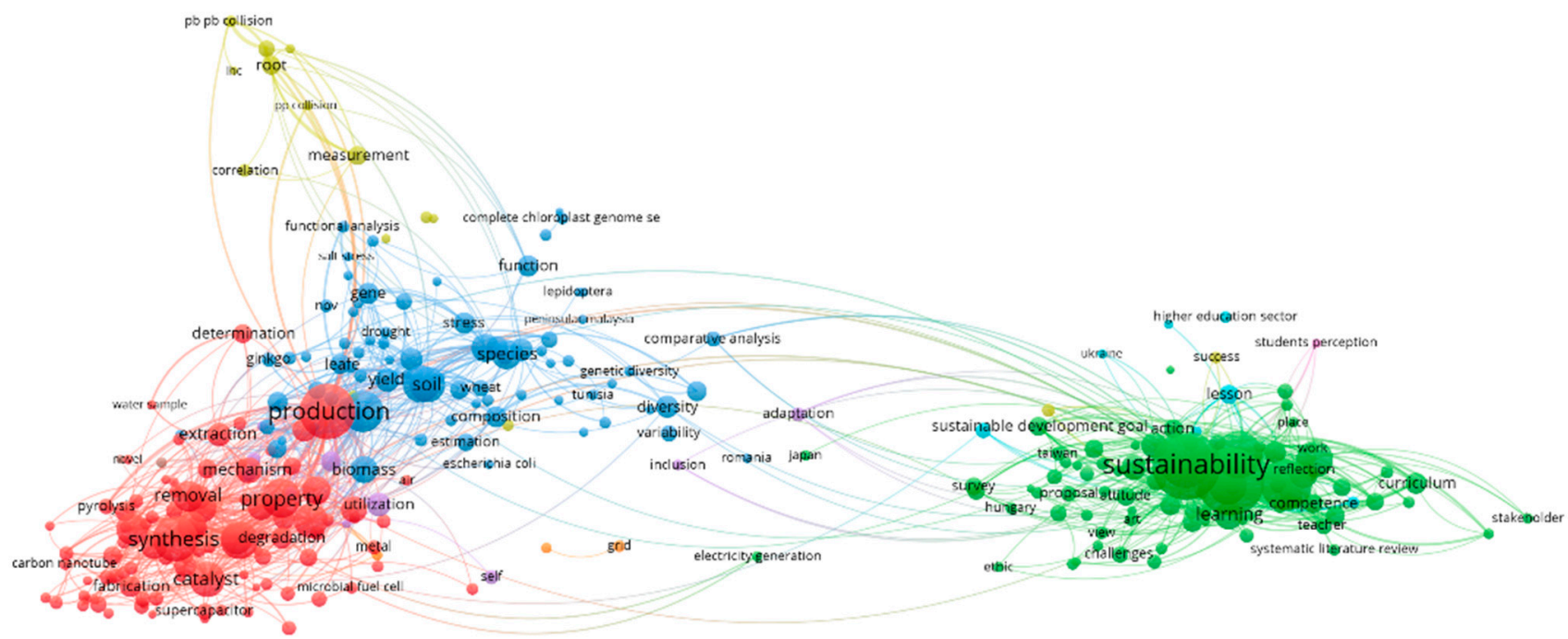

Figure 7. Web of Science publications clustered according to key term co-occurrences, obtained by title text mining. Source: Authors (visualization performed in VOS Viewer).

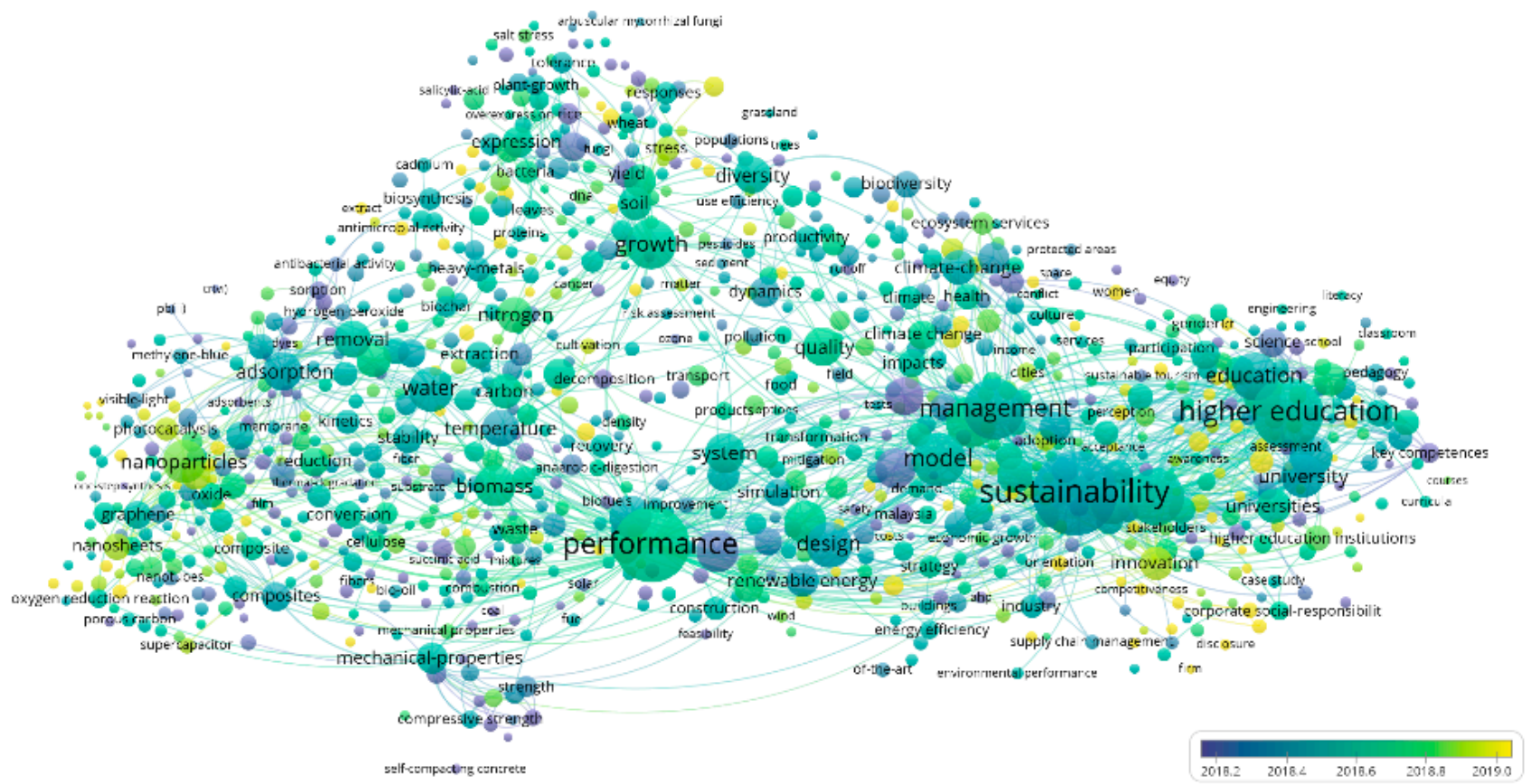

Figure 8. Web of Science publications clustered according to author-supplied key term co-occurrence dynamics. Source: Authors (visualization performed in VOS Viewer).

Similar visualizations were performed for the publication corpus, using the Scopus data for the first 2000 bibliometric records (due to the limitations of the Scopus reporting engine) and the VOS Viewer text mining functionalities. The co-occurrence analysis, based on author-supplied keywords, resulted in as many as 11 clusters, which could not be interpreted meaningfully. However, the co-occurrence analysis obtained by text mining of both publications' titles and abstracts provided some interesting insights (see Figure 10). The analysis was technically viable, regardless of the limited technical resources, since the 
number of bibliometric records was limited to 2000, due to the internal Scopus reporting policies. Therefore, these limitations should be taken into account when considering the results of the Scopus analysis.

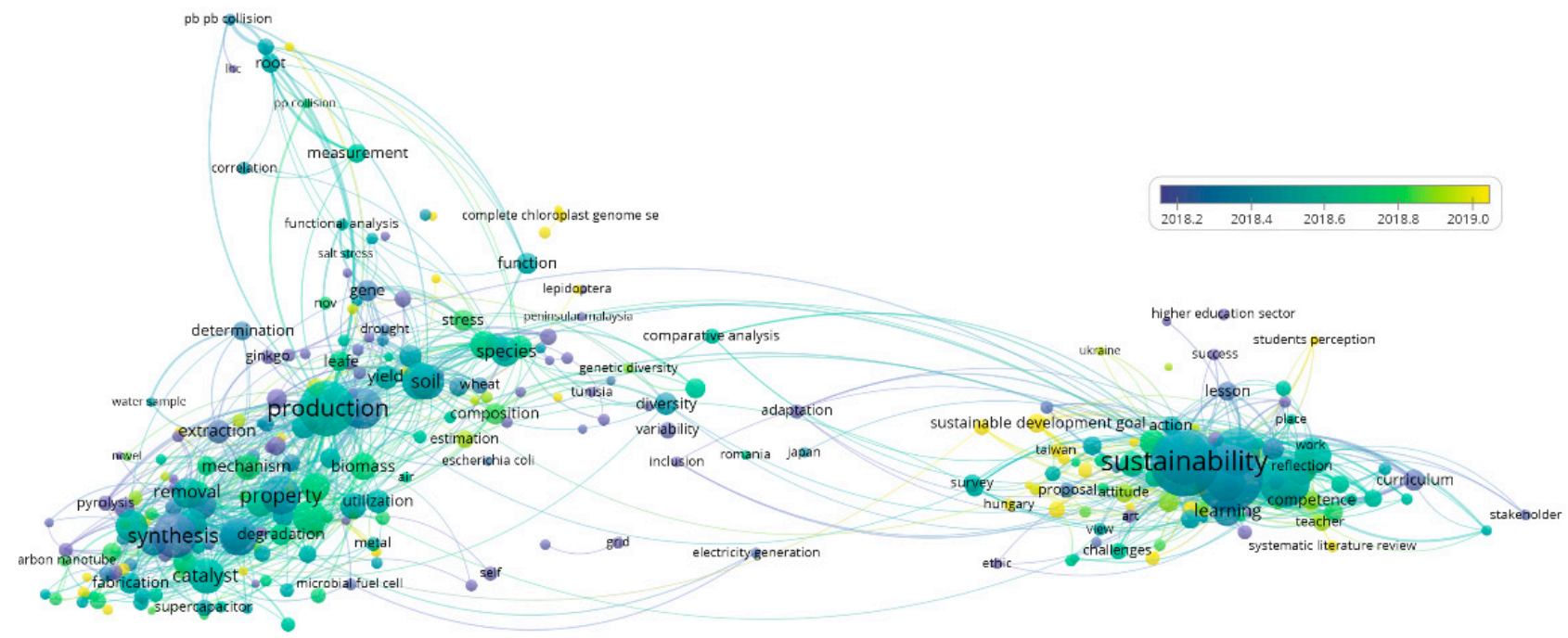

Figure 9. Web of Science publications clustered according to key term co-occurrence dynamics, obtained by title text mining. Source: Authors (visualization performed in VOS Viewer).

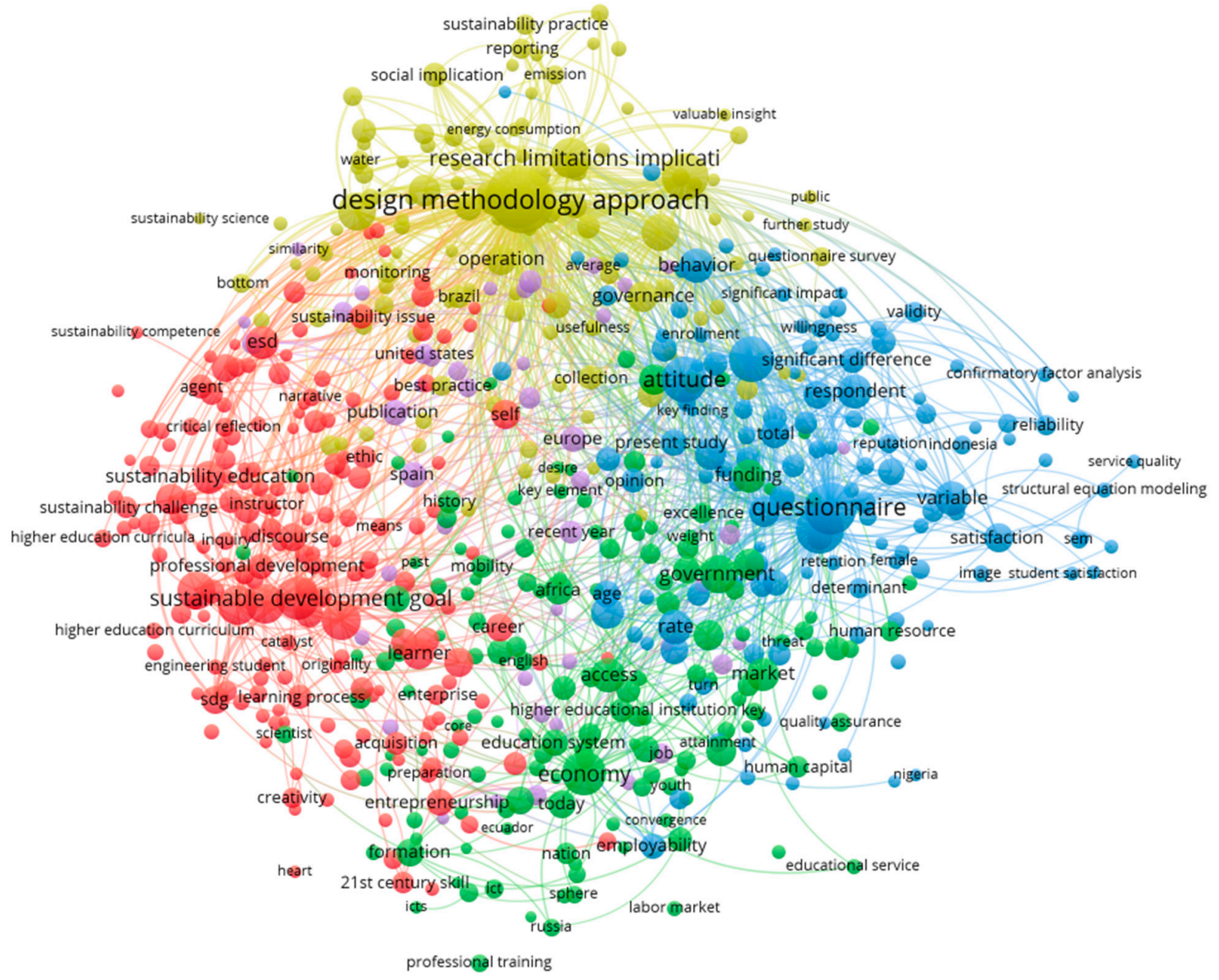

Figure 10. Scopus publications clustered according to key term co-occurrences, obtained by title text mining. Source: Authors (visualization performed in VOS Viewer). 
Text mining identified clusters related to the study of higher education, the education system and their orientation toward the SDGs (determined by the red color); sustainability practices in higher education, including campus sustainability, energy, and water consumption, design methodologies, research originality and its practical implications (yellow); student-focused empirical research (blue); analysis of market-education and stakeholder linkages (green) and a marginal cluster, focusing on best practices and academic research in individual nations (violet). This subset of the much broader WoS corpus, consisting mainly of studies from social science fields, shows a relatively high level of collaboration among researchers in social science when considering the sustainability and economic relevance of higher education. Analysis of Scopus key term co-occurrence dynamics (see Figure 11) shows a transition from the focus on campus greening and research implications, to higher education and education system (blue and green items on the map), to student-focused topics, SDGs, and employability (yellow items).

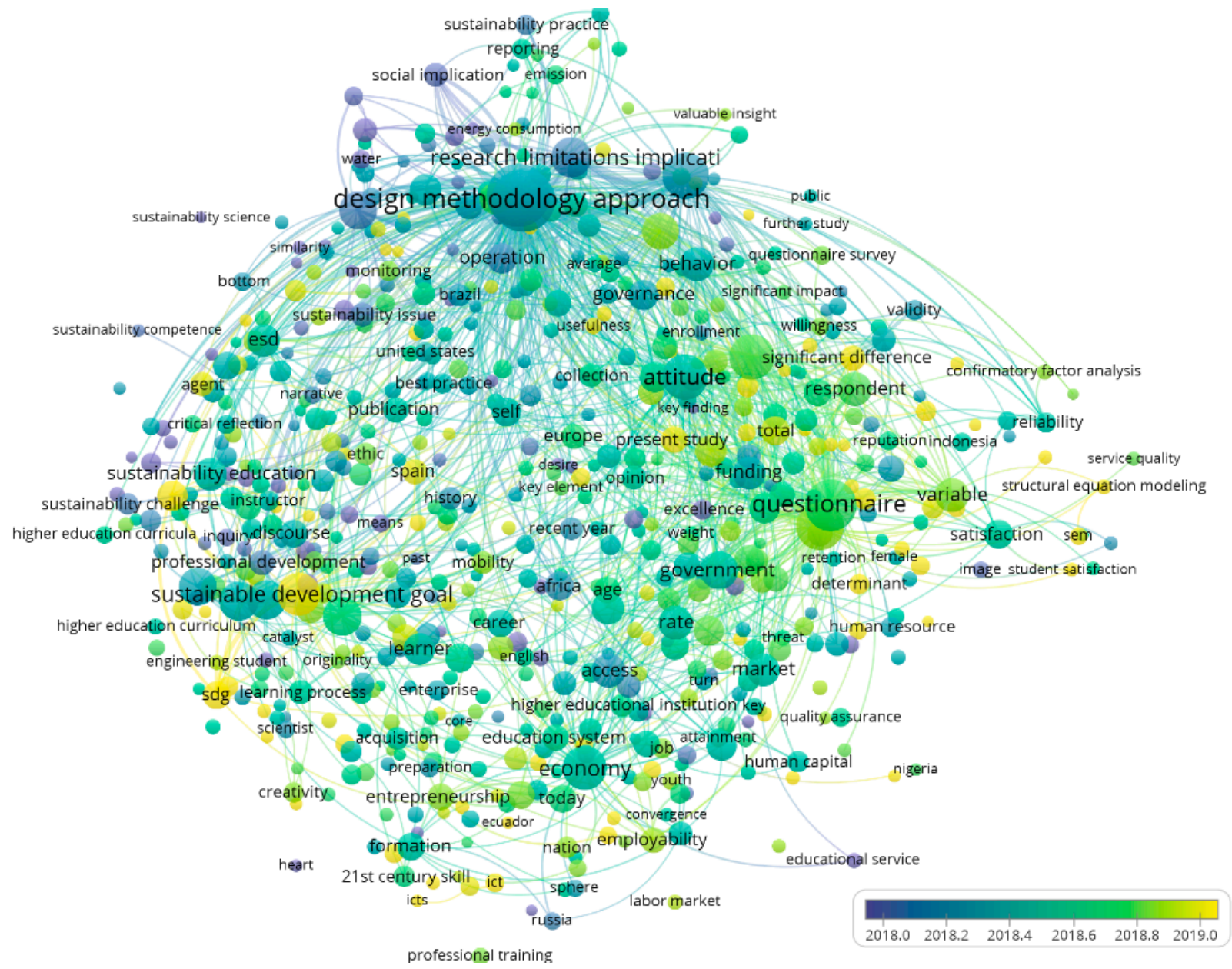

Figure 11. Scopus publications clustered according to key term co-occurrence dynamics, obtained by title text mining. Source: Authors (visualization performed in VOS Viewer).

The obtained results of the bibliographic analysis fully support our proposition on the need to continue research on creating innovative skillsets and ensuring sustainable development by higher education, as well as by examining how multi-disciplinary and multi-sector collaboration can assist these processes. While the international cooperation seems to be adequate, the extant research practices are still not as inter-disciplinary, as currently stated by the researchers, once one ventures outsides of the realm of the social sciences. This can be concluded from comparing key terms co-occurrence maps, obtained by using the author-specified keywords and the key terms extracted by the text mining 
procedures. In addition, the industry-academic collaboration in the existing research corpus is negligent, supported by the findings related to SDG bibliometric mapping and the lack of connections among the educational and natural/technical fields when the visualizations of the research landscapes are performed.

\section{Conclusions}

Ensuring sustainability remains a significant task of higher education and its institutions, which can be concluded based on the previously reported empirical results related to the extant literature, referred by WoS and Scopus indexing databases. However, a vast body of knowledge related to sustainability, its implementation, and the role of the higher education sector in ensuring sustainable development has put the empirical analysis of the 21st-century skills to be supplied by higher education institutions to the background. Nevertheless, this topic still deserves the full attention of scholars and policy-makers alike.

As reported by the World Economic Forum, for the next four years, growth of $13.5 \%$ in emerging professions is expected-parallel to the decreasing fall of redundant jobs (from $15.4 \%$ to $9 \%$ till 2025). Workers will have to acquire even $40-50 \%$ of new skills during the next five years. Employers expect to offer reskilling and upskilling to $70 \%$ of their employees.

This is creating an unprecedented challenge for everyone, including university teachers, who can contribute a lot but are often not sufficiently aware of the situation's urgency. The same can be said for the respective government departments, which is also applicable to students and the general public.

Moreover, various university rankings do not provide an objective insight into whether a country has developed an optimal university system. Excellence is certainly most welcome and adds to the international prestige of the countries concerned. However, improving the general level of university teaching (i.e., its relevance and quality) is even more critical. This is reflected by the education policy of Nordic and some Baltic governments, not only on the higher education level $[45,46]$, which could further serve as a benchmark and inspiration to other European regions.

This is why the awareness among policy and the educational communities, the professional and general public, and the media of the critical importance of 21st-century skills to be developed during the entire education cycle, including higher education. This notion is confirmed by the bibliometric analysis, which we performed, to support the theoretical identification of the relevant trends in higher education. It confirms that the extant body of knowledge views the integration of the relevant business skills for the 21st century with the outlook and competencies of ensuring sustainable (industrial) development as a key to the further development of the European society and economy.

Some specific recommendations, which could be extended, both to the higher education administrators as well as to the education policy community, include:

- $\quad$ supporting multi-disciplinary research and teaching, not only based on declarations of the multi-disciplinary approach, but rather by adjusting funding and human resource management practices;

- emphasizing the stakeholder (policy, academic, corporate ... actors) dialogue and encouraging joint research;

- reaching out to students and hearing their voice on the proposed higher education policies and reforms.

This also requires adequate and stable funding of higher education institutions, wherever it may come from. While $100 \%$ public funding might not be realistic in all European countries, governments and universities should co-operate in creating a system, which secures the conditions for quality in teaching and research. Many countries have not yet found a reasonable university funding scheme to develop, encourage, and provide the best possible learning outcomes for the highest possible percentage of students to complete their studies and stimulate individual universities to achieve these goals without compromising the strict quality criteria. 
Our proposition and recommendations to researchers, policy-makers, and higher education administrations, might help achieve such a goal.

Author Contributions: Conceptualization, N.A., A.F. and B.A.; methodology, N.A. and A.F.; validation, A.F., B.A. and N.A.; formal analysis, N.A.; investigation, N.A. and A.F.; resources, B.A.; data curation, A.F., B.A. and N.A.; writing-original draft preparation, B.A.; writing-review and editing, A.F., B.A. and N.A.; visualization, A.F., B.A. and N.A. All authors have read and agreed to the published version of the manuscript.

Funding: This research received no specific funding. Authors are grateful to Elsevier BV and its Research Intelligence division for granting access to Elsevier SciVal for the research purposes.

Institutional Review Board Statement: Not applicable.

Informed Consent Statement: Not applicable.

Data Availability Statement: This study is based on publicly available, subscription-based bibliometric data from Clarivate Web of Science and Elsevier Scopus, as licensed by the authors' institutions and/or the relevant institutional funding schemes.

Conflicts of Interest: The authors declare no conflict of interest.

\section{References}

1. Myklebust, J.P. Universities and Colleges Face Wholesale Reforms. University World News, 30 March 2015. Available online: https: / / www.universityworldnews.com/ post.php?story=20150330080046468 (accessed on 1 July 2021).

2. Bridgestock, L. Why Study at A Scandinavian University? Top Universities, 19 April 2021. Available online: https://www. topuniversities.com/student-info/choosing-university/why-study-scandinavian-university (accessed on 1 July 2021).

3. Destination Guides. Why Study in Japan? Top Universities. Available online: https://www.topuniversities.com/where-to-study/ asia/japan/guide (accessed on 1 July 2021).

4. Impact Rankings 2021. Available online: https://www.timeshighereducation.com/rankings/impact/2021/overall\#!/page/0/ length/25/sort_by/rank/sort_order/asc/cols/undefined (accessed on 18 July 2021).

5. A European Green Deal. Available online: https://ec.europa.eu/info/strategy/priorities-2019-2024/european-green-deal_en (accessed on 10 August 2021).

6. 2020 Strategic Foresight Report. Charting the Course Towards a More Resilient Europe. Available online: https: / / ec.europa.eu/ info/sites/default/files/strategic_foresight_report_2020_1_0.pdf (accessed on 15 August 2021).

7. De Nul, L.; Breque, M.; Petridis, A. Industry 5.0. Towards a Sustainable, Human-Centric, and Resilient European Industry. European Commission. 2021. Available online: https://op.europa.eu/en/publication-detail/-/publication/468a892a-5097-11ebb59f-01aa75ed71a1/ (accessed on 10 July 2021).

8. Futures Literacy. Available online: https://en.unesco.org/futuresliteracy/about (accessed on 10 August 2021).

9. Cizelj, B.; Fošner, A. Universities facing Challenges of 21st Century. KEN Weekly Brief. 2020, 3, 1-8.

10. Abad-Segura, E.; González-Zamar, M.D. Sustainable economic development in higher education institutions: A global analysis within the SDGs framework. J. Clean. Prod. 2021, 294, 126133. [CrossRef]

11. Kioupi, V.; Voulvoulis, N. Sustainable development goals (SDGs): Assessing the contribution of higher education programmes. Sustainability 2020, 12, 6701. [CrossRef]

12. SDSN Australia/Pacific. Getting Started with the SDGs in Universities: A Guide for Universities, Higher Education Institutions, and the Academic Sector; Australia, New Zealand and Pacific Edition; Sustainable Development Solutions Network-Australia/Pacific: Melbourne, Australia, 2017.

13. UNESCO. Education for Sustainable Development Goals: Learning Objectives; UNESCO: Paris, France, 2017.

14. Chankseliani, M.; McCowan, T. Higher education and the Sustainable Development Goals. High. Educ. 2021, 81, 1-8. [CrossRef]

15. Haddock-Fraser, J.; Rands, P.; Scoffham, S. Leadership for Sustainability in Higher Education; Bloomsbury Publishing: London, UK, 2018.

16. Franco, I.; Saito, O.; Vaughter, P.; Whereat, J.; Kanie, N.; Takemoto, K. Higher education for sustainable development: Actioning the global goals in policy, curriculum and practice. Sustain. Sci. 2019, 14, 1621-1642. [CrossRef]

17. Leal Filho, W.; Eustachio, J.H.; Caldana, A.C.; Will, M.; Lange Salvia, A.; Rampasso, I.S.; Anholon, R.; Platje, J.; Kovaleva, M. Sustainability leadership in higher education institutions: An overview of challenges. Sustainability 2020, 12, 3761. [CrossRef]

18. Brown, R.; Werbeloff, L.; Raven, R. Interdisciplinary research and impact. Glob. Chall. 2019, 3, 1900020. [CrossRef]

19. Paul, S. University environmental Hackathons to further the sustainable development goals. In Sustainable Development Goals and Institutions of Higher Education; Nhamo, G., Mjimba, V., Eds.; Springer: Berlin/Heidelberg, Germany, 2020; pp. 131-140.

20. Daub, C.H.; Hasler, M.; Verkuil, A.H.; Milow, U. Universities talk, students walk: Promoting innovative sustainability projects. Int. J. Sustain. High. Educ. 2020, 21, 97-111. [CrossRef] 
21. Trencher, G.; Yarime, M.; McCormick, K.B.; Doll, C.N.; Kraines, S.B. Beyond the third mission: Exploring the emerging university function of co-creation for sustainability. Sci. Public Policy 2014, 41, 151-179. [CrossRef]

22. Leal Filho, W.; Muthu, N.; Edwin, G.; Sima, M. (Eds.) Implementing Campus Greening Initiatives: Approaches, Methods and Perspectives; Springer: Berlin/Heidelberg, Germany, 2015.

23. Staniškis, J.K. Sustainable university: Beyond the third mission. Environ. Res. Eng. Manag. 2016, 72, 8-20. [CrossRef]

24. Kumari, R.; Kwon, K.S.; Lee, B.H.; Choi, K. Co-creation for social innovation in the ecosystem context: The role of higher educational institutions. Sustainability 2020, 12, 307. [CrossRef]

25. Cooke, P.; De Propris, L. For a resilient, sustainable and creative European economy, in what ways is the EU important? In Innovation, Global Change and Territorial Resilience; Cooke, P., Parrilli, M.D., Curbelo, J.L., Eds.; Edward Elgar Publishing: Cheltenham, UK, 2012.

26. OECD Future of Education and Skills 2030. Conceptual Learning Framework. 2021. Available online: https: / /www.oecd.org/ education/2030-project/teaching-and-learning/learning/skills/Skills_for_2030.pdf (accessed on 2 August 2021).

27. Stauffer, B. What Are 21st Century Skills? 2020. Available online: https://www.aeseducation.com/blog/what-are-21st-centuryskills (accessed on 10 July 2021).

28. Palmer, T. Fifteen Characteristics of a 21st-Century Teacher. Available online: https://www.edutopia.org/discussion/15 -characteristics-21st-century-teacher (accessed on 10 July 2021).

29. Adams, R.; Jeanrenaud, S.; Bessant, J.; Denyer, D.; Overy, P. Sustainability-oriented Innovation: A Systematic Review. Int. J. Manag. Rev. 2016, 18, 180-205. [CrossRef]

30. Körfgen, A.; Förster, K.; Glatz, I.; Maier, S.; Becsi, B.; Meyer, A.; Kromp-Kolb, H.; Stötter, J. It'sa hit! Mapping Austrian research contributions to the sustainable development goals. Sustainability 2018, 10, 3295. [CrossRef]

31. Agnew, K.; Francescon, D.; Martin, R.; Rhannam, M.; Schemm, Y.; Balisciano, M.; Bayazit, K.; Bos, C.; Erkal, E.; Falk-Krzesinski, H.J.; et al. The Power of Data to Advance the SDGs: Mapping research for the Sustainable Development Goals. Elsevier. 2020. Available online: https:/ / www.elsevier.com/connect/sdg-report (accessed on 29 October 2021).

32. Times Higher Education, Times Higher Education Impact Rankings Methodology 2021. Version 1.3. 2021, Times Higher Education. Available online: https://www.timeshighereducation.com/sites/default/files/breaking_news_files/the_impactrankings_ methodology_2021_v1.3_final.pdf (accessed on 29 October 2021).

33. Ananiadou, S.; Procter, R.; Thomas, J. Supporting Systematic Reviews Using Text Mining. Soc. Sci. Comput. Rev. 2009, 27, 509-523. [CrossRef]

34. Zupic, I.; Čater, T. Bibliometric Methods in Management and Organization. Organ. Res. Methods 2015, 18, 429-472. [CrossRef]

35. Van Eck, N.J.; Waltman, L. Citation-based clustering of publications using CitNetExplorer and VOSviewer. Scientometrics 2017, 111, 1053-1070. [CrossRef]

36. Van Eck, N.J.; Waltman, L. Software survey: VOSviewer, a computer program for bibliometric mapping. Scientometrics 2010, 84, 523-538. [CrossRef]

37. Hensley, N. The Future of Sustainability in Higher Education. J. Sustain. Educ. 2017, 13. Available online: http://www. susted.com/wordpress/wp-content/uploads /2017/03/Hensley-JSE-March-2017-Future-Casting-Issue-PDF.pdf (accessed on 8 October 2021).

38. Friman, M.; Schreiber, D.; Mutanen, A.; Perälä, S.; Salminen, J. Wicked problems: University research topic convergence despite divergence in local educational and innovation policies. Int. J. Sustain. High. Educ. 2021, 22, 108-124. [CrossRef]

39. Keep, E.; Mayhew, K. Inequality_'Wicked problems', labour market outcomes and the search for silver bullets. Oxf. Rev. Educ. 2014, 40, 764-781. [CrossRef]

40. Ramley, J.A. The changing role of higher education: Learning to deal with wicked problems. J. High. Educ. Outreach Engagem. 2014, 18, 7-22.

41. Rijavec, D.; Pevcin, P. The analysis of a public administration crisis situation: The case of migrations in Slovenia. Manag. J. Contemp. Manag. Issues 2021, 26, 81-99. [CrossRef]

42. Žigman, A.; Ridzak, T.; Dumičić Jemrić, M. Crisis management in public institutions-Croatian financial system and the Covid-19 pandemic. Manag. J. Contemp. Manag. Issues 2021, 26, 1-16.

43. Van Eck, N.J.; Waltman, L. Visualizing bibliometric networks. In Measuring Scholarly Impact; Springer: Cham, Switzerland, 2014; pp. 285-320.

44. Sinoara, R.A.; Antunes, J.; Rezende, S.O. Text mining and semantics: A systematic mapping study. J. Braz. Comput. Soc. 2017, 23, 9. [CrossRef]

45. Ingpórsson, Á.H.; Alfirević, N.; Pavičić, J.; Vican, D. (Eds.) Educational Leadership in Policy: Challenges and Implementation within Europe; Palgrave/Springer: London, UK, 2018.

46. Moos, L.; Alfirevic, N.; Pavicic, J.; Koren, A.; Cacija, L.N. (Eds.) Educational Leadership, Improvement and Change: Discourse and Systems in Europe; Palgrave/Springer: London, UK, 2020. 